NBER WORKING PAPER SERIES

\title{
WHY DO CONSUMER PRICES REACT LESS THAN IMPORT PRICES TO EXCHANGE RATES?
}

\author{
Philippe Bacchetta \\ Eric van Wincoop \\ Working Paper 9352 \\ http://www.nber.org/papers/w9352 \\ NATIONAL BUREAU OF ECONOMIC RESEARCH \\ 1050 Massachusetts Avenue \\ Cambridge, MA 02138 \\ November 2002
}

Paper written for the $17^{\text {th }}$ Annual Congress of the European Economic Association, Venice, August 2002. We would like to thank Richard Friberg and participants of the 2002 EEA Congress for comments and Marco Cavaliere and Tim Frech for able research assistance. Bacchetta's work on this paper is part of a research network on 'The Analysis of International Capital Markets: Understanding Europe's Role in the Global Economy,' funded by the European Commission under the Research Training Network Program (Contract No. HPRN-CT-1999-00067). The views expressed herein are those of the authors and not necessarily those of the National Bureau of Economic Research.

(C) 2002 by Philippe Bacchetta and Eric van Wincoop. All rights reserved. Short sections of text, not to exceed two paragraphs, may be quoted without explicit permission provided that full credit, including (C) notice, is given to the source. 
Why Do Consumer Prices React less than Import Prices to Exchange Rates?

Philippe Bacchetta and Eric van Wincoop

NBER Working Paper No. 9352

November 2002

JEL No. F4

\section{$\underline{\text { ABSTRACT }}$}

It is well known that the extent of pass-through of exchange rate changes to consumer prices is much lower than to import prices. One explanation is local distribution costs. Here we consider an alternative, complementary, explanation based on the optimal pricing strategies of firms. We consider a model where foreign exporting firms sell intermediate goods to domestic firms. Domestic firms assemble the imported intermediate goods and sell final goods to consumers. When domestic firms face significant competition from other domestic final goods producing sectors (e.g., the non-traded goods sector) we show that they prefer to price in domestic currency, while exporting firms tend to price in the exporter's currency. In that case the pass-through to import prices is complete, while the pass-through to consumer prices is zero.

Philippe Bacchetta

Study Center Gerzensee

University of Lausanne

3115 Gerzensee, Switzerland

and CEPR
Eric van Wincoop

Department of Economics

University of Virginia

Charlottesville, VA 22901

and NBER

vanwincoop@virginia.edu 


\section{Introduction}

The pass-through of exchange rate changes to domestic prices is a key factor in the transmission of shocks and the adequate policy response in open economies. Traditional open-economy macroeconomic models have paid little attention to this. For example, most flexible price monetary models assume full pass-through by assuming purchasing power parity.

Since recent theoretical developments in open-economy macroeconomics are based on microfoundations, they enable a deeper analysis of this issue. In particular, in the literature that follows Obstfeld and Rogoff (1995), and where monopolistic producers preset their prices, a special role is given to the degree of pass-through. In effect, exporters can decide to set their price either in their own currency or in the consumers' currency. These have been referred to as respectively PCP (producer currency pricing) and LCP (local currency pricing). In the last few years numerous researchers have examined the different implications of the pricing strategies for the impact of shocks, optimal exchange rate and monetary policy, trade, capital flows, and welfare. ${ }^{1}$

Some investigators, such as Betts and Devereux (1996) and ourselves (Bacchetta and van Wincoop (2000)), have used evidence of limited passthrough to consumer prices and the resulting close relationship between nominal and real exchange rates, as a justification for models with consumer currency pricing. Others, such as Obstfeld and Rogoff (2000), have argued that the relationship between the terms of trade and exchange rates is consistent with models of producer currency pricing, and inconsistent with models of consumer currency pricing. However, neither the LCP nor the PCP assumption is consistent with both pieces of evidence. The heart of the issue is that the degree of pass-through of exchange rates to consumer prices is much lower than the pass-through to import prices. The former is close to zero (e.g., see McCarthy, 1999), while the median estimate of the latter is about 50 percent. ${ }^{2}$ Most models do not make a distinction between the extent of pass-through to import prices and consumer prices.

The recent literature has adopted two, possibly complementary, modeling approaches to account for the lower degree of pass-through to consumer than

\footnotetext{
${ }^{1}$ See Lane (2001) for a survey of New Open Economy Macroeconomics models and Engel (2002) for a survey of the literature on exchange rates and prices.

${ }^{2}$ See Goldberg and Knetter (1997) for a review of the literature and Campa and Goldberg (2002) for the most recent evidence.
} 
import prices. ${ }^{3}$ In the first approach, imported goods have to go through a distribution sector to reach consumers. If 'tradable' goods sold to consumers incorporate a significant share of local value added, consumer prices will not be so sensitive to exchange rate changes. Burstein, Neves, and Rebelo (2002) and Burstein, Eichenbaum, and Rebelo (2002) show that the role of local inputs in the distribution sector is quantitatively important. However, they also show that it cannot fully explain the difference in pass-through. ${ }^{4}$

In the second approach imports are intermediate goods, often mixed with domestically produced goods to produce a final good sold to consumers. In that case pricing decisions are made at two different levels, intermediate goods producers and final goods producers. Obstfeld (2001) presents a framework where there is purchasing power parity, and therefore full passthrough, at the level of intermediate goods producers, but zero pass-through to consumer prices by final goods producers. ${ }^{5}$ Final goods producers, who combine domestic and foreign intermediate goods, are assumed exogenously to set prices in the local currency. ${ }^{6}$

In this paper we propose an explanation for the difference in pass-through based on the firms' optimal pricing strategy. We adopt the second approach, where imported goods are intermediate goods. Although we have no doubt that local distribution costs are an important part of the explanation for the lower degree of pass-through to consumer prices, here we will abstract from that explanation by assuming that imported intermediate goods are not mixed with local value added to produce consumption goods. We follow an approach developed in Bacchetta and van Wincoop (2002), henceforth BW, where firms optimally decide in which currency to preset prices. ${ }^{7}$ In our previous work firms sell directly to consumers, so that there is no difference between import and consumer prices. The basic result is that the currency in which prices are set depends on competitive pressure in an industry. When

\footnotetext{
${ }^{3}$ See Engel (2002) for further discussion.

${ }^{4}$ Corsetti and Dedola (2002) also consider a model in which the pass-through to consumer prices is lower than to import prices as a result of local distribution costs. In their setup the pass-through to import prices is incomplete as monopolistically competitive exporters take into account that the demand from importers is affected by the presence of local distribution costs.

${ }^{5}$ See also McCallum and Nelson (1999).

${ }^{6}$ The objective of Obstfeld (2001) is to show that a zero pass-through to consumer prices does not imply that an economy is insulated from exchange rate changes.

${ }^{7}$ Other papers that look at the endogenous currency decision include Devereux, Engel and Storgaard (2002) and Corsetti and Pesenti (2002).
} 
firms face less competition, they are more likely to set prices in their own currency.

We present a highly stylized model in order to better crystallize the point we are making. Monopolistically competitive exporters sell intermediate goods to monopolistically competitive final good producers. In order to sharpen our results we assume that final goods producers only use foreign intermediate goods. We argue that final goods producers are more likely to set their price in the local currency than intermediate goods exporters. ${ }^{8}$ Final goods producers need to compete with all the goods purchased by consumers, including non-traded goods. On the other hand, intermediate goods producers only compete with other intermediate goods producers. In this context we show that if the non-tradable sector is large enough, a likely equilibrium is that exporters set prices in the exporter's currency and final goods producers set prices in domestic currency, implying full pass-through to import prices and no pass-through to consumer prices. Even though the importing final goods producers face exchange-rate risk on their cost side, they prefer to set the price in domestic currency to avoid large price fluctuations relative to other consumer goods.

Non-tradable goods play a crucial role for our results. However, the reason they matter is different from the existing literature, where non-tradables are used to produce consumer goods. In our context, non-tradables matter by affecting consumer's demand. The model is described in section 2. Section 3 presents the main results and Section 4 concludes. The full analysis is found in the Appendix.

\section{An Auto-Parts Model}

The model is an extension of BW, assuming that exports are not sold directly to consumers, but are intermediate goods, as in Obstfeld (2001). Consider an industry with a continuum of foreign intermediate goods producers of mass one. They sell to a continuum of domestic final goods producers. The final goods producers only use imported intermediate goods as inputs. One can think of an auto-parts model, where imported parts are assembled to

\footnotetext{
${ }^{8}$ The alternative where final goods producers set prices in the exporter's currency may seem rather odd, but it can be thought of as an ex-ante choice of full pass-through. This is along the lines of Corsetti and Pesenti (2001), where firms preset a pass-through function rather than the price itself.
} 
produce the final product and no local input is required in this process. There is another final good sector producing a non-tradable good involving only domestic inputs. We will refer to the sector that assembles the imported intermediate goods as the final goods sector and the other domestic sector as the non-tradables sector, even though they both produce final consumer goods.

\section{Consumers}

Domestic consumers derive utility from both a non-tradable good and final goods:

$$
U=\left(n c_{N}^{\frac{\mu-1}{\mu}}+(1-n) c_{F}^{\frac{\mu-1}{\mu}}\right)^{\frac{\mu}{\mu-1}}
$$

where $0<n<1$ measures the size of the non-tradable sector in consumption; $c_{N}$ is a non-traded consumption good and $c_{F}$ is an index of final goods:

$$
c_{F}=\left(\int_{0}^{1} c_{i}^{\frac{\mu_{F}-1}{\mu_{F}}} d i\right)^{\frac{\mu_{F}}{\mu_{F}-1}}
$$

The elasticity of substitution between final and non-tradable goods is given by $\mu$, while the elasticity among final goods is given by $\mu_{F}$. If we normalize aggregate demand to one, the optimal demand for final good $i$ is then given by:

$$
c_{i}=\frac{1-n}{n}\left(\frac{p_{i}}{p_{F}}\right)^{-\mu_{F}}\left(\frac{p_{F}}{P}\right)^{-\mu}
$$

where $p_{i}$ is the price of good $i, p_{F}$ is the price index of final goods, and $P$ is CPI. We assume that the price of the non-tradable good is given (for example because the non-tradable sector is competitive and faces a fixed wage).

\section{Final goods producers}

The output of final good producer $i, Y_{i}$, is given by the CES 'assembling' function:

$$
Y_{i}=\left(\int_{0}^{1} I_{i j}^{\frac{\mu_{I}-1}{\mu_{I}}} d j\right)^{\frac{\mu_{I}}{\mu_{I}-1} \frac{1}{\eta_{F}}}
$$

where $I_{i j}$ are imported intermediate goods from exporter $j, \mu_{I}>1$ is the elasticity of substitution among the various intermediate goods, and $\eta_{F} \geq 1$ is a convexity parameter in the production function. 
Final good producers face demand given by (3). They maximize their expected utility $E U(\Pi)$, where $U($.$) is concave and profits \Pi$ are equal to the value of sales minus the cost of intermediate goods. Final goods producers choose in which currency to preset their price (due to menu costs), at what level to set that price, and how much to purchase from intermediate goods producers. The total demand for imported good $j$ is given by:

$$
I_{j}=\left(\frac{q_{j}}{q}\right)^{-\mu_{I}} Y^{\eta_{F}}
$$

where $q_{j}$ is the price of exporter $j$ expressed in domestic currency, $q$ is the import price index, and $Y^{\eta_{F}}=\int_{0}^{1} Y_{i}^{\eta_{F}} d i$.

\section{Exporters}

Exporters face the demand given by (5) and have a cost function given by $w^{*} I_{j}^{\eta_{I}}$, where $w^{*}$ is a constant wage rate in foreign currency and $\eta_{I} \geq 1$ is a convexity parameter.

\section{Optimal Pricing Strategies}

We assume that the nominal exchange rate $S$ (units of domestic currency per unit of foreign currency) is the only random variable and is given exogenously. ${ }^{9}$ Since firms set prices before the exchange rate is known, it matters whether the price is set in domestic or foreign currency. A difference in passthrough between import and consumer prices then occurs when exporters are more likely to price in their own currency and final goods producers prefer pricing in domestic currency. ${ }^{10}$

In this section we examine the equilibria where firms choose optimally the currency in which they set their price. Our basic strategy is to assume some currency pricing for both exporters and final goods producers and determine under what condition a marginal firm (either foreign or domestic) would

\footnotetext{
${ }^{9}$ In BW, we consider a general equilibrium model and show that results are similar to a partial equilibrium model if nominal wages are rigid. In this short paper, we only consider partial equilibrium.

${ }^{10}$ Formally, we only consider the extreme cases of full or zero pass-through. In an economy with several sectors, the pass-through would be the average across sectors.
} 
deviate from this equilibrium. When a marginal firm has no incentive to deviate, we have a Nash equilibrium. ${ }^{11}$

\section{Exporters}

Intermediate goods exporting firms can either set their price in their own currency, $q_{j}^{*}$, or in the importers' currency, $q_{j}$. Let $\widetilde{\Pi}_{j}^{E}\left(\widetilde{\Pi}_{j}^{I}\right)$ denote profits of a marginal firm $j$ when the price is set in the exporter's (importer's) currency. The profits expressed in foreign currency are:

$$
\begin{aligned}
\widetilde{\Pi}_{j}^{E} & =q_{j}^{*} I_{j}^{E}-w^{*} \cdot\left(I_{j}^{E}\right)^{\eta_{I}} \\
\widetilde{\Pi}_{j}^{I} & =\frac{q_{j}}{S} I_{j}^{I}-w^{*} \cdot\left(I_{j}^{I}\right)^{\eta_{I}}
\end{aligned}
$$

where $I_{j}^{E}$ and $I_{j}^{I}$ are equal to demand in (5). The demand faced by exporters differs when the price is set in domestic or in foreign currency. Consider (5) and assume that $q$ and $Y^{\eta_{F}}$ are given. Then, $I_{j}^{E}$ depends on $S$, as $q_{j}=S q_{j}^{*}$, but $I_{j}^{I}$ is constant. In this case, the marginal exporter faces a trade-off between price uncertainty (with importer's currency pricing) and quantity uncertainty (with exporter's currency pricing). As shown in BW (Proposition 2), the preferred strategy in this case depends in particular on the demand price elasticity, $\mu_{I}$, as it determines the degree of quantity uncertainty.

However, in general $q$ and $Y^{\eta_{F}}$ are not constant and are conditional on other firms' pricing. Overall, there are four possible cases, since each sector (intermediate and final goods) can price either in domestic or in foreign currency. Thus, we need to find the optimal pricing strategy for a marginal exporting firm in the four cases.

\section{Final goods producers}

Domestic producers can set their price either in domestic currency, $p_{i}$, or in foreign currency, $p_{i}^{*}$. Profits expressed in domestic currency are :

$$
\begin{aligned}
\Pi_{i}^{E} & =S p_{i}^{*} c_{i}^{E}-q \cdot\left(c_{i}^{E}\right)^{\eta_{F}} \\
\Pi_{i}^{I} & =p_{i} c_{i}^{I}-q \cdot\left(c_{i}^{I}\right)^{\eta_{F}}
\end{aligned}
$$

where $c_{i}^{E}$ and $c_{i}^{I}$ are given in (3). Here again, demand faced by a marginal firm depends on its pricing strategy. When $q$ and $p_{F}$ are given, a marginal

\footnotetext{
${ }^{11}$ We focus on symmetric and pure equilibria. Equilibria in mixed strategies exist in some cases, but can be shown to be unstable.
} 
firm prefers pricing in domestic currency as it faces both price and quantity uncertainty when pricing in the exporter's currency. However, when exporters price in their own currency, $q=S q^{*}$, so that there is also cost uncertainty for domestic goods producers. In this case final goods firms may prefer pricing in the foreign currency to hedge cost risk.

In general, there are again four cases to analyze depending on the pricing strategy of other exporters and final good producers.

\section{Equilibrium}

By analyzing the optimal strategy of a marginal firm, we can determine under what conditions the four cases mentioned above are equilibria. We do this for small levels of risk and use the same procedure as in BW (using Lemma 1). The full derivation is tedious and can be found in the Appendix. To get clearer insights, we focus on a subset of the cases in the following two propositions.

Proposition 1 Assume that final goods producers set their price in the domestic currency. Then pricing in the exporter's currency is always an equilibrium for the intermediate goods exporting firms. It is the unique equilibrium when $\left(\eta_{I}-1\right) \mu_{I}<1$ and the Pareto-superior equilibrium otherwise. ${ }^{12}$

When $\mu_{I}$ is large enough, there are two (pure strategy) equilibria as pricing in the importer's currency is also an equilibrium for exporters. However, if exporters can coordinate on the currency in which they set their price, they choose to set the price in their own currency. In that case they will face neither price risk, nor demand risk. There is no demand risk since all competitors set the price in the same currency.

Proposition 2 Assume that exporters set their price in the exporting currency. Then an equilibrium in the final goods sector is given by:

- Pricing in domestic currency when $\left(\eta_{F}-1\right) \mu_{F}>1$

- Pricing in the exporter's currency when $\left(\eta_{F}-1\right)\left(\mu_{F}-2 n \mu\right)>-1$

\footnotetext{
${ }^{12}$ Proposition 1 is similar to Proposition 2 in BW when the market share of the exporting country is large. In the current model, the market share is one since final goods producers only use imported intermediate goods.
} 
The optimal pricing strategy in the final goods sector depends on the size of non-tradeable goods sector $n$. When $n$ is small, pricing in the exporter's currency is always an equilibrium and we get two equilibria when $\mu_{F}$ is large. However, when $n$ is large the second condition in Proposition 2 does not necessarily hold and the only equilibrium may be pricing in domestic currency. In this case final good producers prefer not to pass through their variation in cost because of the large price fluctuations relative to the nontraded goods sector that it would imply. This scenario becomes more likely the higher the elasticity of substitution $\mu$ between final goods and non-traded goods and therefore the competition that final goods producers face in the domestic market. This is the extreme case where there is no pass-through to consumer prices and full pass-through to import prices (combined with Proposition 1, we know that this is an equilibrium). Even though Propositions 1 and 2 do not fully characterize all equilibria, they represent the most interesting cases. ${ }^{13}$

\section{Conclusions}

We have presented a framework where domestic firms import goods priced in foreign currency and sell them in domestic currency. Even though they are subject to exchange rate risk on their cost side, they prefer pricing in local currency due to competitive pressure in the domestic market. Our explanation is complementary to the distribution cost explanation offered in the literature: if the final good also needs domestic inputs in its production, it is even more likely that final goods producers price in domestic currency.

The analysis can be extended in several directions. First, we could consider an alternative industrial structure where exporters and importers engage in bilateral bargaining (e.g., Bilson, 1983) instead of monopolistic competition. Second, there might be other reasons for price stickiness than menu costs at the level of producers. Finally, another obvious extension is to introduce the above analysis in a general equilibrium framework.

\footnotetext{
${ }^{13}$ For example, from the Appendix, we see that if exporters decide to price in the importer's currency, the final goods producers will also find it optimal to use their own currency since their cost no longer varies with the exchange rate.
} 


\section{References}

[1] Bacchetta, P. and van Wincoop, E. (2000), "Does Exchange Rate Stability Increase Trade and Welfare?" American Economic Review, 90(4), 1093-1109.

[2] Bacchetta, P. and van Wincoop, E. (2002), "A Theory of the Currency Denomination of International Trade," National Bureau of Economic Research Working Paper No. 9039.

[3] Betts, C. and M. Devereux (1996), "The Exchange Rate in a Model of Pricing-To-Market," European Economic Review 40, 1007-1021.

[4] Bilson, J. F.O. (1983), "The Choice of an Invoice Currency in International Transactions," in J.S. Bhandari and B.H. Putnam (eds.), Economic Interdependence and Flexible Exchange Rates, MIT Press.

[5] Campa, J. M. and L. S. Goldberg (2002), "Exchange Rate Pass-Through into Import Prices: A Macro or Micro Phenomenon," National Bureau of Economic Research Working Paper No. 8934.

[6] Burstein, A., M. Eichenbaum, and S. Rebelo (2002), "Why are Rates of Inflation So Low After Large Devaluations?" National Bureau of Economic Research Working Paper No. 8748.

[7] Burstein, A., J. Neves, and S. Rebelo (2002), "Distribution Costs and Real Exchange Rate Dynamics During Exchange-Rate-Based Stabilizations," Journal of Monetary Economics, forthcoming.

[8] Corsetti, G. and P. Pesenti (2002), "Self-Validating Optimum Currency Areas," working paper, Federal Reserve Bank of New York.

[9] Corsetti, G. and P. Pesenti (2001), "International Dimensions of Optimal Monetary Policy," National Bureau of Economic Research Working Paper No. 8230.

[10] Corsetti, G. and L. Dedola (2002), "Macroeconomics of International Price Discrimination," mimeo.

[11] Devereux, M. B., and C. Engel and Peter E. Storgaard (2002), "Endogenous Exchange Rate Pass-through when Nominal Prices are set in Advance, " working paper, University of Wisconsin. 
[12] Engel, Charles (2002), "Expenditure Switching and Exchange Rate Policy," forthcoming in NBER Macroeconomics Annual 2002.

[13] Goldberg, P. and M. Knetter (1997), "Goods Prices and Exchange Rates: What Have We Learned?" Journal of Economic Literature, 12431272 .

[14] Lane, P.R. (2001), "The New Open Economy Macroeconomics: A Survey," Journal of International Economics 54, 235-266.

[15] McCallum, B.T., and E. Nelson (1999), "Nominal Income Targeting in an Open-Economy Optimizing Model," Journal of Monetary Economics $43,553-578$.

[16] McCarthy, J. (1999) "Pass-through of Exchange Rates and Import Prices to Domestic Inflation in Some Industrialized Economies," Working Paper No. 79, Bank for International Settlements.

[17] Obstfeld, M. (2001), "International Macroeconomics: Beyond the Mundell-Fleming Model," IMF Staff Papers 47, 1-39.

[18] Obstfeld, M. and K. Rogoff (1995), "Exchange Rate Dynamics Redux," Journal of Political Economy 103, 624-60.

[19] Obstfeld, M. and K. Rogoff (2000), "New Directions for Stochastic Open Economy Models," Journal of International Economics, 50, 117-153. 


\section{A Technical Appendix}

\section{A.1 Introduction}

The objective of this Appendix is to characterize the set of symmetric pure strategy Nash equilibria. Propositions 1 and 2 are then simply derived from this characterization.

The strategy is to consider the incentives of a marginal firm, either in the final goods or in the intermediate goods sector, in choosing a currency in which to set the price. A marginal intermediate good exporter will prefer pricing in the exporter's currency when $U\left(\widetilde{\Pi}^{E}\right)>U\left(\widetilde{\Pi}^{I}\right)$, where $U\left(\widetilde{\Pi}^{E}\right)$ $\left[U\left(\widetilde{\Pi}^{I}\right)\right]$ represents the utility of profits when pricing in the exporter's currency [importer's currency]. Similarly, a final good producer prefers pricing in the exporter's currency when $U\left(\Pi^{E}\right)>U\left(\Pi^{I}\right)$. To evaluate the preferred pricing strategy, we follow the approach developed in Bacchetta and van Wincoop (2002) by considering small levels of risk. In particular, we apply Lemma 1 of that paper. Since the first order derivative of profits with respect to the exchange rate at the deterministic equilibrium is always the same for exporter's and importer's currency pricing, we only have to compare the second order derivatives. The Lemma tells us that a firm prefers to price in the exporter's (importer's) currency if the second order derivative of profits with respect to the exchange rate is larger (smaller) when setting the price in the exporter's currency than when setting the price in the importer's currency. These derivatives are computed at the deterministic equilibrium.

A firm's profits depend on what other firms do in both sectors. An equilibrium is given when the incentives of the marginal firm are consistent with aggregate behavior. There are four cases to consider:

- CASE (E,I): exporters choose exporter's currency pricing and final goods producers choose importer's currency pricing.

- CASE (E,E): both exporters and final goods producers choose exporter's currency pricing.

- CASE (I,I): both exporters and final goods producers choose importer's currency pricing. 
- CASE (I,E): exporters choose importer's currency pricing and final goods producers choose exporter's currency pricing.

The results for the four cases are summarized in Table 1. Before analyzing these four cases, we compute the equilibrium prices in the deterministic equilibrium.

\section{A.1.1 Final good equilibrium price}

We need to evaluate the optimal prices in the absence of exchange rate risk at $S=1$. In this case, the currency in which prices are set is irrelevant for profits, so that $\Pi_{i}^{I}=\Pi_{i}^{E}=\Pi_{i}$. From equations (3) and (9) in the text, profits for the marginal final good producer $i$ are given by:

$$
\Pi_{i}=p_{i}\left(\frac{1-n}{n}\right)\left(\frac{p_{i}}{p_{F}}\right)^{-\mu_{F}}\left(\frac{p_{F}}{P}\right)^{-\mu}-q\left[\left(\frac{1-n}{n}\right)\left(\frac{p_{i}}{p_{F}}\right)^{-\mu_{F}}\left(\frac{p_{F}}{P}\right)^{-\mu}\right]^{\eta_{F}}
$$

The first order condition of $\Pi_{i}$ with respect to $p_{i}$ yields:

$$
-\left(\mu_{F}-1\right) p_{i}^{-\mu_{F}}\left(\frac{1-n}{n}\right) p_{F}^{\mu_{F}-\mu} P^{\mu}+q \mu_{F} \eta_{F} p_{i}^{-\mu_{F} \eta_{F}-1}\left[\left(\frac{1-n}{n}\right) p_{F}^{\mu_{F}-\mu} P^{\mu}\right]^{\eta_{F}}=0
$$

In equilibrium all prices $p_{i}$ are equal, i.e., $p_{i}=p_{F}$. This, together with the assumption that units are chosen such that $p_{N}=p_{F}=P$ gives the optimal final good price $\bar{p}$ :

$$
\bar{p}=\frac{\mu_{F} \eta_{F}}{\mu_{F}-1}\left(\frac{1-n}{n}\right)^{\eta_{F}-1} \bar{q}
$$

where $\bar{q}$ is the optimal price set by exporters in the deterministic equilibrium.

\section{A.1.2 Equilibrium intermediate good price}

Using equations (5) and (6) in the text yields the profit for the marginal exporter $j$ :

$$
\widetilde{\Pi}_{j}=q_{j}^{*}\left(\frac{q_{j}^{*}}{q^{*}}\right)^{-\mu_{I}} Y^{\eta_{F}}-w^{*}\left[\left(\frac{q_{j}^{*}}{q^{*}}\right)^{-\mu_{I}} Y^{\eta_{F}}\right]^{\eta_{I}}
$$


The first order condition of $\tilde{\Pi}_{j}$ with respect to $q_{j}^{*}$ yields:

$$
\frac{\partial \widetilde{\Pi}_{j}}{\partial q_{j}^{*}}=-\left(\mu_{I}-1\right)\left(q_{j}^{*}\right)^{-\mu_{I}}\left(q^{*}\right)^{\mu_{I}} Y^{\eta_{F}}+w^{*} \mu_{I} \eta_{I}\left(q_{j}^{*}\right)^{-\mu_{I} \eta_{I}-1}\left(q^{*}\right)^{\mu_{I} \eta_{I}} Y^{\eta_{F} \eta_{I}}=0
$$

In equilibrium all prices $q_{j}^{*}$ are equal, i.e., $q_{j}^{*}=q^{*}$. The optimal intermediate good price $\bar{q}$ is then given by:

$$
\bar{q}=\frac{\mu_{I} \eta_{I}}{\mu_{I}-1}\left(Y^{\eta_{F}}\right)^{\eta_{I}-1} w^{*}
$$

\section{A.2 Case (E,I)}

We will denote with $\Pi_{S S}^{I}$ and $\Pi_{S S}^{E}$ the second order derivatives of profits at the deterministic equilibrium. When $\Pi_{S S}^{E}-\Pi_{S S}^{I}>(<) 0$ a final good producer prefers pricing in the exporter's (importer's) currency. An analogue condition is valid for exporters.

\section{A.2.1 (E,I): Condition for final good producers}

If a final good producer chooses importer's currency pricing, its demand function (3) in the text and profit function $(9)$ in the text can be rewritten as:

$$
\begin{gathered}
c^{I}=\frac{1-n}{n} \\
\Pi^{I}=\bar{p}\left(\frac{1-n}{n}\right)-S \bar{q}\left(\frac{1-n}{n}\right)^{\eta_{F}}
\end{gathered}
$$

If, instead, a final good producer chooses exporter's currency pricing, its demand function (3) in the text and profit function $(8)$ in the text are given by:

$$
\begin{gathered}
c^{E}=\frac{1-n}{n} S^{-\mu_{F}} \\
\Pi^{E}=\bar{p}\left(\frac{1-n}{n}\right) S^{1-\mu_{F}}-\bar{q}\left(\frac{1-n}{n}\right)^{\eta_{F}} S^{1-\mu_{F} \eta_{F}}
\end{gathered}
$$

The first order derivatives of profits with respect to $S$ are given by: 


$$
\begin{gathered}
\frac{\partial \Pi^{I}}{\partial S}=-\bar{q}\left(\frac{1-n}{n}\right)^{\eta_{F}} \\
\frac{\partial \Pi^{E}}{\partial S}=\left(1-\mu_{F}\right) \bar{p}\left(\frac{1-n}{n}\right) S^{-\mu_{F}}-\left(1-\mu_{F} \eta_{F}\right) \bar{q}\left(\frac{1-n}{n}\right)^{\eta_{F}} S^{-\mu_{F} \eta_{F}} .
\end{gathered}
$$

The second order derivatives with respect to $S$ evaluated at $S=1$ are given by:

$$
\begin{gathered}
\Pi_{S S}^{I}=0 \\
\Pi_{S S}^{E}=\mu_{F}\left[\left(\mu_{F}-1\right)\left(\frac{1-n}{n}\right) \bar{p}+\eta_{F}\left(1-\mu_{F} \eta_{F}\right)\left(\frac{1-n}{n}\right)^{\eta_{F}} \bar{q}\right]
\end{gathered}
$$

A final good producer prefers importer's currency pricing if $\Pi_{S S}^{I}-\Pi_{S S}^{E}>$ 0, i.e.:

$$
\mu_{F}\left[\left(\mu_{F}-1\right)\left(\frac{1-n}{n}\right) \bar{p}+\eta_{F}\left(1-\mu_{F} \eta_{F}\right)\left(\frac{1-n}{n}\right)^{\eta_{F}} \bar{q}\right]<0
$$

Substituting $\bar{p}$ using (12), we get the no-deviation condition for final good producers (given the assumption that exporters choose exporter's currency pricing):

$$
\mu_{F}\left(\eta_{F}-1\right)>1
$$

\section{A.2.2 (E,I): Condition for exporters}

If an intermediate good exporter chooses the exporter's currency, its import function (5) in the text and profit function $(6)$ in the text can be rewritten as:

$$
\begin{gathered}
I^{E}=Y^{\eta_{F}} \\
\widetilde{\Pi}^{E}=\bar{q} Y^{\eta_{F}}-w^{*} Y^{\eta_{F} \eta_{I}}
\end{gathered}
$$

If, instead, the exporter chooses importer's currency pricing, its import function (5) in the text and profit function ( 7$)$ in the text are given by:

$$
I^{I}=S^{\mu_{I}} Y^{\eta_{F}}
$$




$$
\widetilde{\Pi}^{I}=S^{\mu_{I}-1} \bar{q} Y^{\eta_{F}}-w^{*} S^{\mu_{I} \eta_{I}} Y^{\eta_{F} \eta_{I}}
$$

Taking the derivatives of both profit functions with respect to $S$ yields:

$$
\begin{gathered}
\frac{\partial \widetilde{\Pi}^{E}}{\partial S}=0 \\
\frac{\partial \widetilde{\Pi}^{I}}{\partial S}=S^{\mu_{I}-2}\left(\mu_{I}-1\right) \bar{q} Y^{\eta_{F}}-S^{\mu_{I} \eta_{I}-1} \mu_{I} \eta_{I} w^{*} Y^{\eta_{F} \eta_{I}}
\end{gathered}
$$

The second order derivatives evaluated at $S=1$ are:

$$
\begin{gathered}
\widetilde{\Pi}_{S S}^{E}=0 \\
\widetilde{\Pi}_{S S}^{I}=\left(\mu_{I}-2\right)\left(\mu_{I}-1\right) \bar{q} Y^{\eta_{F}}-\left(\mu_{I} \eta_{I}-1\right) \mu_{I} \eta_{I} w^{*} Y^{\eta_{F} \eta_{I}}
\end{gathered}
$$

An exporter prefers exporter's currency pricing if: $\widetilde{\Pi}_{S S}^{E}-\widetilde{\Pi}_{S S}^{I}>0$, i.e.:

$$
-\left(\mu_{I}-2\right)\left(\mu_{I}-1\right) \bar{q} Y^{\eta_{F}}+\left(\mu_{I} \eta_{I}-1\right) \mu_{I} \eta_{I} w^{*} Y^{\eta_{F} \eta_{I}}>0
$$

Substituting $\bar{q}$ using (15) we get the no-deviation condition for exporters (given the assumption that final good producers choose importer's currency pricing):

$$
\mu_{I}\left(\eta_{I}-1\right)>-1
$$

Since $\eta_{I}>1$ this condition is always satisfied.

\section{A.3 CASE (E,E)}

\section{A.3.1 (E,E): Condition for final good producers}

If a final good producer chooses exporter's currency pricing, its demand and profit functions can be written as:

$$
\begin{gathered}
c^{E}=S^{-\mu}\left(\frac{1-n}{n}\right)\left(\frac{P}{\bar{p}}\right)^{\mu} \\
\Pi^{E}=S^{1-\mu} \bar{p}\left(\frac{1-n}{n}\right)\left(\frac{P}{\bar{p}}\right)^{\mu}-\bar{q} S^{1-\mu \eta_{F}}\left(\frac{1-n}{n}\right)^{\eta_{F}}\left(\frac{P}{\bar{p}}\right)^{\mu \eta_{F}}
\end{gathered}
$$


If, instead, a final good producer chooses importer's currency pricing we have:

$$
\begin{gathered}
c^{I}=S^{\mu_{F}-\mu}\left(\frac{1-n}{n}\right)\left(\frac{P}{\bar{p}}\right)^{\mu} \\
\Pi^{I}=S^{\mu_{F}-\mu} \bar{p}\left(\frac{1-n}{n}\right)\left(\frac{P}{\bar{p}}\right)^{\mu}-S^{1+\eta_{F}\left(\mu_{F}-\mu\right)} \bar{q}\left(\frac{1-n}{n}\right)^{\eta_{F}}\left(\frac{P}{\bar{p}}\right)^{\mu \eta_{F}}
\end{gathered}
$$

To compute the derivatives of profits, we have to take into account that $P / \bar{p}$ depends on $S$. The CPI is given by:

$$
P=\left[n p_{N}^{1-\mu}+(1-n)(S \bar{p})^{1-\mu}\right]^{\frac{1}{1-\mu}}
$$

Together with the equilibrium assumption $p_{N}=\bar{p}$, we can derive the following expression: $P / \bar{p}=\left[n+(1-n) S^{1-\mu}\right]^{\frac{1}{1-\mu}}$. The first and second order derivative of this with respect to $S$ evaluated at $S=1$ are given by:

$$
\begin{gathered}
\left.\frac{\partial(P / \bar{p})}{\partial S}\right|_{S=1}=(1-n) \\
\left.\frac{\partial^{2}(P / \bar{p})}{\partial S^{2}}\right|_{S=1}=-\mu n(1-n)
\end{gathered}
$$

Taking the derivative of both profit functions with respect to $S$ yields:

$$
\begin{aligned}
\frac{\partial \Pi^{E}}{\partial S}= & \bar{p}\left(\frac{1-n}{n}\right)\left[\begin{array}{c}
S^{-\mu}(1-\mu)\left(\frac{P}{\bar{p}}\right)^{\mu} \\
+S^{1-\mu} \mu\left(\frac{P}{\bar{p}}\right)^{\mu-1} \frac{\partial(P / \bar{p})}{\partial S}
\end{array}\right] \\
& -\bar{q}\left(\frac{1-n}{n}\right)^{\eta_{F}}\left[\begin{array}{c}
S^{-\mu \eta_{F}}\left(1-\mu \eta_{F}\right)\left(\frac{P}{\bar{p}}\right)^{\mu \eta_{F}} \\
+S^{1-\mu \eta_{F}} \mu \eta_{F}\left(\frac{P}{\bar{p}}\right)^{\mu \eta_{F}-1} \frac{\partial(P / \bar{p})}{\partial S}
\end{array}\right] \\
\frac{\partial \Pi^{I}}{\partial S}= & \bar{p}\left(\frac{1-n}{n}\right)\left[\begin{array}{c}
S^{\mu_{F}-\mu-1}\left(\mu_{F}-\mu\right)\left(\frac{P}{\bar{p}}\right)^{\mu} \\
+S^{\mu_{F}-\mu} \mu\left(\frac{P}{\bar{p}}\right)^{\mu-1} \frac{\partial(P / \bar{p})}{\partial S}
\end{array}\right] \\
& -\bar{q}\left(\frac{1-n}{n}\right)^{\eta_{F}}\left[\begin{array}{c}
S^{\eta_{F}\left(\mu_{F}-\mu\right)}\left[1+\eta_{F}\left(\mu_{F}-\mu\right)\right]\left(\frac{P}{\bar{p}}\right)^{\mu \eta_{F}} \\
+S^{1+\eta_{F}\left(\mu_{F}-\mu\right)} \mu \eta_{F}\left(\frac{P}{\bar{p}}\right)^{\mu \eta_{F}-1} \frac{\partial(P / \bar{p})}{\partial S}
\end{array}\right]
\end{aligned}
$$


The second order derivatives evaluated at $S=1$ are given by:

$$
\left.\begin{array}{rl}
\Pi_{S S}^{E}= & \bar{p}\left(\frac{1-n}{n}\right)\left[\mu(\mu-1) n^{2}-\mu^{2} n(1-n)\right] \\
& -\bar{q}\left(\frac{1-n}{n}\right)^{\eta_{F}} \eta_{F}\left[\mu\left(\mu \eta_{F}-1\right) n^{2}-\mu^{2} n(1-n)\right] \\
\Pi_{S S}^{I}= & \bar{p}\left(\frac{1-n}{n}\right)\left[\begin{array}{c}
\left(\mu_{F}-\mu\right)\left[\mu_{F}-1+\mu(1-2 n)\right] \\
+\mu(\mu-1)(1-n)^{2}-\mu^{2} n(1-n)
\end{array}\right] \\
& -\bar{q}\left(\frac{1-n}{n}\right)^{\eta_{F}} \eta_{F}\left\{\begin{array}{c}
{\left[1+\eta_{F}\left(\mu_{F}-\mu\right]\left(\mu_{F}-\mu\right)\right.} \\
+2 \mu\left[1+\eta_{F}\left(\mu_{F}-\mu\right](1-n)\right. \\
+\mu\left(\mu \eta_{F}-1\right)(1-n)^{2} \\
-\mu^{2} n(1-n)
\end{array}\right.
\end{array}\right\}
$$

Final good producers prefer exporter's currency pricing if : $\Pi_{S S}^{E}-\Pi_{S S}^{I}>0$. Substituting $\bar{p}$ using (12), we get the no-deviation condition for final good producers (given the assumption that exporters choose exporter's currency pricing too):

$$
\left(\eta_{F}-1\right)\left(\mu_{F}-2 n \mu\right)>-1
$$

\section{A.3.2 (E,E): Condition for exporters}

If final good producers price in exporter's currency, the term $Y^{\eta_{F}}$ is no longer independent of $S$, in contrast to case $(\mathrm{E}, \mathrm{I}) . Y^{\eta_{F}}$ is now given by: ${ }^{14}$

$$
Y^{\eta_{F}}=\left(\frac{1-n}{n}\right)^{\eta_{F}}\left(\frac{S \bar{p}}{P}\right)^{-\mu \eta_{F}}
$$

Taking this into account, we can derive the following import and profit functions for an exporter that chooses exporter's currency pricing:

$$
I^{E}=\left(\frac{1-n}{n}\right)^{\eta_{F}}\left(\frac{P}{S \bar{p}}\right)^{\mu \eta_{F}}
$$

\footnotetext{
${ }^{14}$ Remember that $Y^{\eta_{F}}=\int_{0}^{1} Y_{i}^{\eta_{F}} d i$ and that the market clearing condition is given by: $Y_{i}=c_{i}$.
} 


$$
\widetilde{\Pi}^{E}=\bar{q}\left(\frac{1-n}{n}\right)^{\eta_{F}}\left(\frac{P}{S \bar{p}}\right)^{\mu \eta_{F}}-w^{*}\left(\frac{1-n}{n}\right)^{\eta_{F} \eta_{I}}\left(\frac{P}{S \bar{p}}\right)^{\mu \eta_{F} \eta_{I}}
$$

If, instead, the exporter chooses importer's currency pricing, we have:

$$
\begin{aligned}
I^{I}=\left(\frac{1}{S}\right)^{-\mu_{I}}\left(\frac{1-n}{n}\right)^{\eta_{F}}\left(\frac{P}{S \bar{p}}\right)^{\mu \eta_{F}} \\
\widetilde{\Pi}^{I}=\left(\frac{1}{S}\right)^{1-\mu_{I}} \bar{q}\left(\frac{1-n}{n}\right)^{\eta_{F}}\left(\frac{P}{S \bar{p}}\right)^{\mu \eta_{F}} \\
-\left(\frac{1}{S}\right)^{-\mu_{I} \eta_{I}} w^{*}\left(\frac{1-n}{n}\right)^{\eta_{F} \eta_{I}}\left(\frac{P}{S \bar{p}}\right)^{\mu \eta_{F} \eta_{I}}
\end{aligned}
$$

Taking the derivative of both profit functions with respect to $S$ yields the following results:

$$
\begin{aligned}
\frac{\partial \widetilde{\Pi}^{E}}{\partial S}= & \bar{q}\left(\frac{1-n}{n}\right)^{\eta_{F}} \mu \eta_{F}\left(\frac{P}{S \bar{p}}\right)^{\mu \eta_{F}-1} \frac{\partial\left(\frac{P}{S \bar{p}}\right)}{\partial S} \\
& -w^{*}\left(\frac{1-n}{n}\right)^{\eta_{F} \eta_{I}} \mu \eta_{F} \eta_{I}\left(\frac{P}{S \bar{p}}\right)^{\mu \eta_{F} \eta_{I}-1} \frac{\partial\left(\frac{P}{S \bar{p}}\right)}{\partial S} \\
\frac{\partial \widetilde{\Pi}^{I}}{\partial S}= & \bar{q}\left(\frac{1-n}{n}\right)^{\eta_{F}}\left[\begin{array}{l}
\left(\mu_{I}-1\right) S^{\mu_{I}-2}\left(\frac{P}{S \bar{p}}\right)^{\mu \eta_{F}} \\
\left.+\mu \eta_{F} S^{\mu_{I}-1}\left(\frac{P}{S \bar{p}}\right)^{\mu \eta_{F}-1} \frac{\partial\left(\frac{P}{S \bar{p}}\right)}{\partial S}\right] \\
-
\end{array}\right. \\
& -w^{*}\left(\frac{1-n}{n}\right)^{\eta_{F} \eta_{I}}\left[\begin{array}{c}
\mu_{I} \eta_{I} S^{\mu_{I} \eta_{I}-1}\left(\frac{P}{S \bar{p}}\right)^{\eta_{F} \eta_{I} \mu} \\
+\mu \eta_{F} \eta_{I} S^{\mu_{I} \eta_{I}}\left(\frac{P}{S \bar{p}}\right)^{\mu \eta_{F} \eta_{I}} \frac{\partial\left(\frac{P}{S \bar{p}}\right)}{\partial S}
\end{array}\right]
\end{aligned}
$$

Using

$$
\begin{gathered}
\left.\frac{\partial(P / S \bar{p})}{\partial S}\right|_{S=1}=-n \\
\left.\frac{\partial^{2}(P / S \bar{p})}{\partial S^{2}}\right|_{S=1}=-\mu n(1-n)+2 n
\end{gathered}
$$


second order derivatives at $S=1$ are

$$
\begin{aligned}
\widetilde{\Pi}_{S S}^{E}= & \bar{q}\left(\frac{1-n}{n}\right)^{\eta_{F}} \mu \eta_{F}\left[2 n-\mu n(1-n)+n^{2}\left(\mu \eta_{F}-1\right)\right] \\
& -w^{*}\left(\frac{1-n}{n}\right)^{\eta_{F} \eta_{I}} \mu \eta_{F} \eta_{I}\left[2 n-\mu n(1-n)+n^{2}\left(\mu \eta_{F} \eta_{I}-1\right)\right](54) \\
\widetilde{\Pi}_{S S}^{I}= & \bar{q}\left(\frac{1-n}{n}\right)^{\eta_{F}}\left[\begin{array}{c}
\left(\mu_{I}-1\right)\left(\mu_{I}-2\right)-2\left(\mu_{I}-1\right) \mu \eta_{F} n \\
+\mu \eta_{F}\left(\mu \eta_{F}-1\right) n^{2}+\mu \eta_{F}(2 n-\mu n(1-n))
\end{array}\right] \\
& -w^{*}\left(\frac{1-n}{n}\right)^{\eta_{F} \eta_{I}}\left[\begin{array}{c}
\mu_{I}\left(\mu_{F} \eta_{I}-1\right)-2 \eta_{F} \eta_{I} \mu_{I} \mu n \\
+\mu \eta_{F}\left(\mu \eta_{F} \eta_{I}-1\right) n^{2} \\
+\mu \eta_{F}(2 n-\mu n(1-n))
\end{array}\right]
\end{aligned}
$$

Exporters prefer exporter's currency pricing if : $\widetilde{\Pi}_{S S}^{E}-\widetilde{\Pi}_{S S}^{I}>0$. Substituting $\bar{q}$ using (15), we get the no-deviation condition for exporters (given the assumption that final good producers choose exporter's currency pricing too):

$$
\left(\eta_{I}-1\right)\left(\mu_{I}-2 \mu \eta_{F} n\right)>-1
$$

\section{A.4 CASE (I,I)}

\section{A.4.1 (I,I): Condition for final good producers}

If a final good producer chooses importers currency pricing, demand function is (16) and profit function $(9)$ in the text can be rewritten as:

$$
\Pi^{I}=\bar{p}\left(\frac{1-n}{n}\right)-\bar{q}\left(\frac{1-n}{n}\right)^{\eta_{F}}
$$

If instead, a final good producer chooses exporter's currency pricing, demand function is (18) and profit function (8) in the text is given by:

$$
\Pi^{E}=S^{1-\mu_{F}} \bar{p}\left(\frac{1-n}{n}\right)-S^{-\mu_{F} \eta_{F}} \bar{q}\left(\frac{1-n}{n}\right)^{\eta_{F}}
$$

Taking the derivative of both profit functions with respect to $S$ yields the following results: 


$$
\begin{gathered}
\frac{\partial \Pi^{I}}{\partial S}=0 \\
\frac{\partial \Pi^{E}}{\partial S}=\left(1-\mu_{F}\right) S^{-\mu_{F}} \bar{p}\left(\frac{1-n}{n}\right)+\mu_{F} \eta_{F} S^{-\mu_{F} \eta_{F}-1} \bar{q}\left(\frac{1-n}{n}\right)^{\eta_{F}}
\end{gathered}
$$

The second order derivatives with respect to $S$ evaluated at $S=1$ are given by:

$$
\begin{gathered}
\Pi_{S S}^{I}=0 \\
\Pi_{S S}^{E}=-\mu_{F}\left(1-\mu_{F}\right)\left(\frac{1-n}{n}\right) \bar{p} \\
-\mu_{F} \eta_{F}\left(1+\mu_{F} \eta_{F}\right)\left(\frac{1-n}{n}\right)^{\eta_{F}} \bar{q}
\end{gathered}
$$

Final good producers prefer importer's currency pricing if $\Pi_{S S}^{I}-\Pi_{S S}^{E}>0$, i.e.,:

$$
\mu_{F}\left(1-\mu_{F}\right)\left(\frac{1-n}{n}\right) \bar{p}+\mu_{F} \eta_{F}\left(1+\mu_{F} \eta_{F}\right)\left(\frac{1-n}{n}\right)^{\eta_{F}} \bar{q}<0
$$

Substituting $\bar{p}$ using (12), we get the no-deviation condition for final good producers (given the assumption that exporters choose importer's currency pricing too):

$$
\mu_{F}\left(\eta_{F}-1\right)>-1
$$

This is always satisfied.

\section{A.4.2 (I,I): Condition for exporters}

If an exporter chooses the importer's currency pricing, its import and the profit functions can be written as:

$$
I^{I}=Y^{\eta_{F}}
$$




$$
\widetilde{\Pi}^{I}=\frac{1}{S} \bar{q} Y^{\eta_{F}}-w^{*}\left(Y^{\eta_{F}}\right)^{\eta_{I}}
$$

If, instead, the exporter chooses exporter's currency pricing, we have:

$$
\begin{gathered}
I^{E}=S^{-\mu_{I}} Y^{\eta_{F}} \\
\widetilde{\Pi}^{E}=S^{-\mu_{I}} \bar{q} Y^{\eta_{F}}-w^{*} S^{-\mu_{I} \eta_{I}}\left(Y^{\eta_{F}}\right)^{\eta_{I}}
\end{gathered}
$$

Taking the derivative of both profit functions with respect to $S$ yields the following results:

$$
\begin{gathered}
\frac{\partial \widetilde{\Pi}^{I}}{\partial S}=-S^{-2} \bar{q} Y^{\eta_{F}} \\
\frac{\partial \widetilde{\Pi}^{E}}{\partial S}=-\mu_{I} S^{-\mu_{I}-1} \bar{q} Y^{\eta_{F}}+\mu_{I} \eta_{I} w^{*} S^{-\mu_{I} \eta_{I}-1}\left(Y^{\eta_{F}}\right)^{\eta_{I}}
\end{gathered}
$$

The second order derivatives with respect to $S$ evaluated at $S=1$ are given by:

$$
\begin{gathered}
\widetilde{\Pi}_{S S}^{I}=2 \bar{q} Y^{\eta_{F}} \\
\widetilde{\Pi}_{S S}^{E}=\mu_{I}\left(\mu_{I}+1\right) \bar{q} Y^{\eta_{F}}-\mu_{I} \eta_{I}\left(\mu_{I} \eta_{I}+1\right) w^{*}\left(Y^{\eta_{F}}\right)^{\eta_{I}}
\end{gathered}
$$

Exporters prefer importer's currency pricing if $\widetilde{\Pi}_{S S}^{I}-\widetilde{\Pi}_{S S}^{E}>0$, i.e.,:

$$
-\left(\mu_{I}+2\right)\left(\mu_{I}-1\right) \bar{q} Y^{\eta_{F}}+\mu_{I} \eta_{I}\left(\mu_{I} \eta_{I}+1\right) w^{*}\left(Y^{\eta_{F}}\right)^{\eta_{I}}>0
$$

Substituting $\bar{q}$ using (15), we get the no-deviation condition for exporters (given the assumption that final goods producers choose importer's currency pricing too):

$$
\mu_{I}\left(\eta_{I}-1\right)>1
$$




\section{A.5 CASE (I,E)}

\section{A.5.1 (I,E): Condition for final good producers}

If a final good producer chooses exporter's currency pricing, its demand and profit functions can be written as:

$$
\begin{gathered}
c^{E}=S^{-\mu}\left(\frac{1-n}{n}\right)\left(\frac{P}{\bar{p}}\right)^{\mu} \\
\Pi^{E}=S^{1-\mu} \bar{p}\left(\frac{1-n}{n}\right)\left(\frac{P}{\bar{p}}\right)^{\mu}-\bar{q} S^{-\mu \eta_{F}}\left(\frac{1-n}{n}\right)^{\eta_{F}}\left(\frac{P}{\bar{p}}\right)^{\mu \eta_{F}}
\end{gathered}
$$

If, instead, a final good producer chooses importer's currency pricing, we have:

$$
\begin{gathered}
c^{I}=S^{\mu_{F}-\mu}\left(\frac{1-n}{n}\right)\left(\frac{P}{\bar{p}}\right)^{\mu} \\
\Pi^{I}=S^{\mu_{F}-\mu} \bar{p}\left(\frac{1-n}{n}\right)\left(\frac{P}{\bar{p}}\right)^{\mu}-S^{\mu_{F} \eta_{F}-\mu \eta_{F}} \bar{q}\left(\frac{1-n}{n}\right)^{\eta_{F}}\left(\frac{P}{\bar{p}}\right)^{\mu \eta_{F}}
\end{gathered}
$$

Taking the derivative of both profit functions with respect to $S$ yields the following results:

$$
\begin{aligned}
& \frac{\partial \Pi^{E}}{\partial S}=\bar{p}\left(\frac{1-n}{n}\right)\left[S^{-\mu}(1-\mu)\left(\frac{P}{\bar{p}}\right)^{\mu}+S^{1-\mu} \mu\left(\frac{P}{\bar{p}}\right)^{\mu-1} \frac{\partial P / \bar{p})}{\partial S}\right] \\
& -\bar{q}\left(\frac{1-n}{n}\right)^{\eta_{F}}\left[\begin{array}{c}
-S^{-\mu \eta_{F}-1} \mu \eta_{F}\left(\frac{P}{\bar{p}}\right)^{\mu \eta_{F}} \\
+S^{-\mu \eta_{F}} \mu \eta_{F}\left(\frac{P}{\bar{p}}\right)^{\mu \eta_{F}-1} \frac{\partial(P / \bar{p})}{\partial S}
\end{array}\right] \\
& \frac{\partial \Pi^{I}}{\partial S}=\bar{p}\left(\frac{1-n}{n}\right)\left[S^{\mu_{F}-\mu-1}\left(\mu_{F}-\mu\right)\left(\frac{P}{\bar{p}}\right)^{\mu}+S^{\mu_{F}-\mu} \mu\left(\frac{P}{\bar{p}}\right)^{\mu-1} \frac{\partial(P / \bar{p})}{\partial S}\right] \\
& -\bar{q}\left(\frac{1-n}{n}\right)^{\eta_{F}} \eta_{F}\left[\begin{array}{c}
S^{\mu_{F} \eta_{F}-\mu \eta_{F}-1}\left(\mu_{F} \eta_{F}-\mu \eta_{F}\right)\left(\frac{P}{\bar{p}}\right)^{\mu \eta_{F}} \\
+S^{\mu \eta_{F}-\mu \eta_{F}} \mu \eta_{F}\left(\frac{P}{\bar{p}}\right)^{\mu \eta_{F}-1} \frac{\partial(P / \bar{p})}{\partial S}
\end{array}\right]
\end{aligned}
$$


Using equations (38) and (39), the second order derivatives with respect to $S$ evaluated at $S=1$ are:

$$
\begin{aligned}
\Pi_{S S}^{E}= & \bar{p}\left(\frac{1-n}{n}\right)\left[\mu(\mu-1) n^{2}-\mu^{2} n(1-n)\right] \\
& -\bar{q}\left(\frac{1-n}{n}\right)^{\eta_{F}} \eta_{F}\left[\mu^{2} \eta_{F} n^{2}+\mu-\mu(1-n)^{2}+\mu^{2} n(1-n)\right](80) \\
\Pi_{S S}^{I}= & \bar{p}\left(\frac{1-n}{n}\right)\left[\begin{array}{c}
\left(\mu_{F}-\mu\right)\left(\mu_{F}-1\right)-\left(\mu_{F}-\mu\right) \mu(1-2 n) \\
+\mu(\mu-1)(1-n)^{2}-\mu^{2} n(1-n)
\end{array}\right] \\
& -\bar{q}\left(\frac{1-n}{n}\right)^{\eta_{F}} \eta_{F}\left\{\begin{array}{c}
\left(\mu_{F}-\mu\right)\left[\eta_{F}\left(\mu_{F}-\mu\right)-1\right] \\
+2 \mu \eta_{F}\left(\mu_{F}-\mu\right)(1-n) \\
+\mu\left(\mu \eta_{F}-1\right)(1-n)^{2}-\mu^{2} n(1-n)
\end{array}\right\}(81)
\end{aligned}
$$

Final good producers prefer exporter's currency pricing if : $\Pi_{S S}^{E}-\Pi_{S S}^{I}>0$. Substituting $\bar{p}$ using (12), we get the no-deviation condition for final good producers (given the assumption that exporters choose importer's currency pricing too):

$$
\left(\eta_{F}-1\right)\left(\mu_{F}-2 n \mu\right)>1
$$

\section{A.5.2 (I,E): Condition for exporters}

Define: $S^{*}=1 / S$. If an exporter chooses importer's currency pricing its import and profit functions can be written as:

$$
\begin{gathered}
I^{I}=\left(\frac{1-n}{n}\right)^{\eta_{F}}\left(\frac{P S^{*}}{\bar{p}}\right)^{\mu \eta_{F}} \\
\widetilde{\Pi}^{I}=S^{*} \bar{q}\left(\frac{1-n}{n}\right)^{\eta_{F}}\left(\frac{P S^{*}}{\bar{p}}\right)^{\mu \eta_{F}}-w^{*}\left(\frac{1-n}{n}\right)^{\eta_{F} \eta_{I}}\left(\frac{P S^{*}}{\bar{p}}\right)^{\mu \eta_{F} \eta_{I}}
\end{gathered}
$$

If, instead, the exporter chooses exporter's currency pricing, we have:

$$
I^{E}=\left(S^{*}\right)^{\mu_{I}}\left(\frac{1-n}{n}\right)^{\eta_{F}}\left(\frac{P S^{*}}{\bar{p}}\right)^{\mu \eta_{F}}
$$


$\widetilde{\Pi}^{E}=\left(S^{*}\right)^{\mu_{I}} \bar{q}\left(\frac{1-n}{n}\right)^{\eta_{F}}\left(\frac{P S^{*}}{\bar{p}}\right)^{\mu \eta_{F}}-w^{*}\left(\frac{1-n}{n}\right)^{\eta_{F} \eta_{I}}\left(S^{*}\right)^{\mu_{I} \eta_{I}}\left(\frac{P S^{*}}{\bar{p}}\right)^{\mu \eta_{F} \eta_{I}}$

Taking derivatives of both profit functions with respect to $S^{*}$ yield the following results:

$$
\begin{aligned}
& \frac{\partial \widetilde{\Pi}^{I}}{\partial S^{*}}=\bar{q}\left(\frac{1-n}{n}\right)^{\eta_{F}}\left[\left(\frac{P S^{*}}{\bar{p}}\right)^{\mu \eta_{F}}+S^{*} \mu \eta_{F}\left(\frac{P S^{*}}{\bar{p}}\right)^{\mu \eta_{F}-1} \frac{\partial\left(\frac{P S^{*}}{\bar{p}}\right)}{\partial S^{*}}\right] \\
& -w^{*}\left(\frac{1-n}{n}\right)^{\eta_{F} \eta_{I}} \mu \eta_{F} \eta_{I}\left(\frac{P S^{*}}{\bar{p}}\right)^{\mu \eta_{F} \eta_{I}-1} \frac{\partial\left(\frac{P S^{*}}{\bar{p}}\right)}{\partial S^{*}} \\
& \frac{\partial \widetilde{\Pi}^{E}}{\partial S^{*}}=\bar{q}\left(\frac{1-n}{n}\right)^{\eta_{F}}\left[\begin{array}{c}
\mu_{I}\left(S^{*}\right)^{\mu_{I}-1}\left(\frac{P S^{*}}{\bar{p}}\right)^{\mu \eta_{F}} \\
+\mu \eta_{F}\left(S^{*}\right)^{\mu_{I}}\left(\frac{P S^{*}}{\bar{p}}\right)^{\mu \eta_{F}-1} \frac{\partial\left(\frac{P S^{*}}{\overline{\bar{p}}}\right)}{\partial S^{*}}
\end{array}\right] \\
& -w^{*}\left(\frac{1-n}{n}\right)^{\eta_{F} \eta_{I}}\left[\begin{array}{c}
\mu_{I} \eta_{I}\left(S^{*}\right)^{\mu_{I} \eta_{I}-1}\left(\frac{P S^{*}}{\bar{p}}\right)^{\mu \eta_{F} \eta_{I}} \\
+\mu \eta_{F} \eta_{I}\left(S^{*}\right)^{\mu_{I} \eta_{I}}\left(\frac{P S^{*}}{\bar{p}}\right)^{\mu \eta_{F} \eta_{I}-1} \frac{\partial\left(\frac{P S^{*}}{\bar{p}}\right)}{\partial S^{*}}
\end{array}\right]
\end{aligned}
$$

Using

$$
\begin{gathered}
\left.\frac{\partial\left(P S^{*} / \bar{p}\right)}{\partial S^{*}}\right|_{S=1}=n \\
\left.\frac{\partial^{2}\left(P S^{*} / \bar{p}\right)}{\partial\left(S^{*}\right)^{2}}\right|_{S=1}=\mu n(n-1),
\end{gathered}
$$

second order derivatives at $S=1$ are

$$
\begin{aligned}
\widetilde{\Pi}_{S^{*} S^{*}}^{E}= & \bar{q}\left(\frac{1-n}{n}\right)^{\eta_{F}}\left[\begin{array}{c}
\mu_{I}\left(\mu_{I}-1\right)+2 n \mu \mu_{I} \eta_{F} \\
+n^{2} \mu \eta_{F}\left(\mu \eta_{F}-1\right)+n \mu^{2} \eta_{F}(n-1)
\end{array}\right] \\
& -w^{*}\left(\frac{1-n}{n}\right)^{\eta_{F} \eta_{I}}\left[\begin{array}{c}
\mu_{I} \eta_{I}\left(\mu_{I} \eta_{I}-1\right)+2 n \mu \mu_{I} \eta_{I}^{2} \eta_{F} \\
+n^{2} \mu \eta_{F} \eta_{I}\left(\mu \eta_{F} \eta_{I}-1\right) \\
+\mu^{2} n \eta_{F} \eta_{I}(n-1)
\end{array}\right]
\end{aligned}
$$




$$
\begin{aligned}
\widetilde{\Pi}_{S^{*} S^{*}}^{I}= & \bar{q}\left(\frac{1-n}{n}\right)^{\eta_{F}}\left[2 \mu \eta_{F} n+\mu \eta_{F}\left(\mu \eta_{F}-1\right) n^{2}+\mu^{2} \eta_{F} n(n-1)\right] \\
& -w^{*}\left(\frac{1-n}{n}\right)^{\eta_{F} \eta_{I}}\left[\begin{array}{c}
\mu \eta_{F} \eta_{I}\left(\mu \eta_{F} \eta_{I}-1\right) n^{2} \\
\left.+\mu^{2} \eta_{F} \eta_{I} n(n-1)\right)
\end{array}\right]
\end{aligned}
$$

Exporters prefer importer's currency pricing if : $\widetilde{\Pi}_{S^{*} S^{*}}^{E}-\widetilde{\Pi}_{S^{*} S^{*}}^{I}>0$. Substituting $\bar{p}$ using (12), we get the no-deviation condition for exporters (given the assumption that final good producers choose exporter's currency pricing):

$$
\left(\eta_{I}-1\right)\left(\mu_{I}+2 \mu \eta_{F} n\right)>1
$$




\begin{tabular}{|l|l|l|}
\cline { 2 - 3 } \multicolumn{1}{c|}{} & $\begin{array}{l}\text { Final good pruducers } \\
\text { choose exporter's } \\
\text { currency pricing }\end{array}$ & $\begin{array}{l}\text { Final good pruducers } \\
\text { choose importer's } \\
\text { currency pricing }\end{array}$ \\
\hline $\begin{array}{l}\text { exporters } \\
\text { choose } \\
\text { exporter's cur- } \\
\text { rency pricing }\end{array}$ & CASE (E,E): & CASE (E,I): \\
\hline $\begin{array}{l}\text { exporters } \\
\text { choose } \\
\text { importer's cur- } \\
\text { rency pricing }\end{array}$ & $\left.\left(\eta_{F}-1\right)\left(\mu_{F}-2 n \mu\right)>-1\right)\left(\mu_{I}-2 \mu \eta_{F} n\right)>-1$ & $\mu_{F}\left(\eta_{F}-1\right)>1$ \\
$\mu_{I}\left(\eta_{I}-1\right)>-1$
\end{tabular}

Table 1 Conditions for Pure Strategy Nash Equilibria 